verify the consistency of his 18 -figure values for $\operatorname{Ei}(44)$ and $\operatorname{Ei}(45)$ with the adjacent entries in his table.

Applied Mathematics Laboratory

JOHN W. WRENCH, JR.

David Taylor Model Basin

Washington 7, D. C.

1. Frank E. Harris, "Tables of the exponential integral $\operatorname{Ei}(x)$," $M T A C$, v. 11, 1957, p. 9-16.

258.-Carl-Erik Fröberg, Hexadecimal Conversion Tables, C. W. K. Gleerup, Lund, Sweden, 1957, ( $M T A C$, Review 82, v. 11, 1957, p. 208.)

The following erratum has been found:

Page 11, for $0 .{ }^{2} 65$ 00D41 DF3B6 45A1D read $0 .{ }^{2} 65$ 00D4F DF3B6 45A1D.

CARL-ERIK FröBERG

University of Lund

Lund, SWEDEN

\title{
NOTES
}

\section{Acknowledgments to Referees}

The editors of Mathematical Tables and Other Aids to Computation were happy to take advantage of the action of the Council of the American Mathematical Society at their December 1956 meeting in Rochester, New York, and furnish to them a list of persons who have refereed papers for $M T A C$ during 1955-1956. This list was incorporated with names furnished by various other journals and published on pages 27 and 28 of AMERICAN MATHEMATICAL SOCIETY NOTICES, April 1957. The editors of $M T A C$ deeply appreciate the services rendered by its referees.

$$
\text { C. B. T. }
$$

\section{The Illinois Journal of Mathematics}

The Illinois Journal of Mathematics is devoted to the publication of original research papers in pure and applied mathematics. The first two issues of this journal have appeared with the tables of contents listed below.

Contents, Vol. 1, No. 1

March, 1957

A fundamental inequality in the theory of valuations, by I. S. Cohen $\&$ Oscar Zariski

Kompakte projektive Ebenen, by Hans Freudenhthal

Homology of Noetherian rings and local rings, by John Tate

Finite dimensionality of certain transformation groups, by Deane Montgomery

On modules of trivial cohomology over a finite group, by Tadasi Nakayama Markoff processes and potentials I, by G. A. Hunt

Inequalities for asymmetric entire functions, by R. P. Boas, Jr.

On a class of linear differential equations with periodic coefficients, by Jack K. Hale 
On a problem of Picard concerning symmetric compositums of functionfields, by Jun-ichi Igusa

On matrix classes corresponding to an ideal and its inverse, by Olga Taussky

Contents, Vol. 1, No. 2

June, 1957

Classes of finite groups and their properties, by Reinhold Baer

The irreducible representations of a semi group related to the symmetric group, by Edwin Hewitt \& Herbert S. Zuckerman

On Ingham's trigonometric inequality, by L. J. Mordell

Fonctions aléatoires à correlation lineaire, by Paul Levy

Sur la corissance radiale d'une fonction méromorphe, by Paul Malliavan

On some applications of dynamic programming to matrix theory, by Richard Bellman

Manuscripts intended for publication in this journal may be written in English, French, German, or Italian and should be addressed to the Illinois Journal of Mathematics or one of the following editors:

Reinhold Baer, Mathematisches Seminar der Universität, Frankfurt am Main, Schumannstrasse 58, Germany.

J. L. Doob, Department of Mathematics, University of Illinois, Urbana, Illinois.

A. H. Taub, Department of Mathematics, University of Illinois, Urbana, Illinois.

George W. Whitehead, Massachusetts Institute of Technology, Cambridge 39, Massachusetts.

Oscar Zariski, Department of Mathematics, Harvard University, 2 Divinity Avenue; Cambridge 38, Massachusetts.

A. H. TAUB

\section{Policy Committee for Mathematics, Technical Advisory Committee to the National Bureau of Standards, Annual Report, May, 1957}

1. The Bureau of Standards Technical Advisory Committee for Mathematics has reviewed the work of the Applied Mathematics Division of the Bureau (Division 11) and finds that in spite of the difficulty this division is having in maintaining its present staff and acquiring new staff, it is providing very excellent mathematical, computational, and statistical services to other agencies of the government as well as to other Bureau divisions. The four sections of Division 11; Numerical Analysis Section (11.01), the Computation Laboratory (11.02), the Statistical Engineering Laboratory (11.03) and the Mathematical Physics Section (11.04), have interesting, useful and imaginative research and training programs which make them effective organizations for the discharge of their responsibilities.

2. The Numerical Analysis section (11.01) has continued its outstanding work in modern Numerical Analysis and the use of computing machines in pursuing research problems in mathematics. In addition it has inaugurated a training program in numerical analysis for senior university staff. 
The purpose of this program is to give regular university staff heretofore specializing in fields different from numerical analysis, a training in that field which will enable them to direct the operation of a university computing center, and to organize training and research in numerical analysis on their return to their own institutions. Thirteen people began work on this program on February 11, 1957 and continued to be in residence at the Bureau of Standards until June 7, 1957. The funds for stipends to the participants and other expenses in connection with this training program were supplied by the National Science Foundation.

Trainees were taught programming for SEAC and were given a very intensive course of lectures on classical numerical analysis, linear equations and matrix inversion, quadrature and ordinary differential equations, characteristic values of matrices, partial differential equations, integral equations, linear programming, and non-linear equations. In addition lectures were given covering a variety of other topics including recursive functions and Turing machines, statistical calculations, discrete variable problems, and some experimental mathematical calculations.

The lecturers included, in addition to members of the staff of the Applied Mathematics Division of the Bureau, mathematicians of note presently engaged in research on one or more of the topics listed above.

This training program should greatly stimulate teaching and research in numerical analysis in universities. It complements the work being done at some universities and does not conflict with it since the universities are in the main concerned with the training of students and this program has as its trainees established mathematicians.

3. The Computation Laboratory (Section 11.02) like other sections of the Division, is having difficulty in maintaining its staff. If this situation is viewed as an educational service to the community in that it furnishes to industry and to other agencies of the government young people with good training in computing procedures, the Bureau may well take pride in the role it is playing.

However, the problem is a difficult one, particularly as the Section experiences a need for the expansion of its staff to provide for the increased work it must undertake with the delivery of the IBM 704 and the obligation to provide some programming help to DOFL.

The Handbook of Mathematical Tables is progressing well. The Section is to be particularly commended for drawing into the work experts in the special phases of mathematics that are represented either by securing the temporary services of these experts at the Bureau, or by contracting out the preparation of specific parts of the book.

4. Statistical Engineering Laboratory (Section 11.03) has as a major activity the consulting with scientists in other divisions of the Bureau on statistical aspects of their problems, including design of experiment and analysis of results. It is performing this function well, and its services are in great demand. The SEL continues to be a center of basic research in experimental design; ten research papers in experimental design are in process of publication in various technical journals. The reliability study recently undertaken by SEL has made a good beginning and promises to produce valuable results.

5. Mathematical Physics Section (11.04) carries on fundamental research on 
problems of its own, and has the function of providing high level specialist consulting services to other parts of the Bureau in the field of mathematical physics. The committee finds that a good program of work is going forward within the limitations of the small staff available.

The idea of having a central consulting group on difficult problems of mathematical physics to serve the rest of the Bureau is sound and commendable. But it can only function effectively if its staff includes creative scientists of the highest caliber. By its nature the work cannot be carried on effectively by persons in the lower ranks. It follows necessarily that this section:must develop in a way that its staff will have considerably higher than average grade ratings as compared with the rest of the Bureau of other comparable scientific laboratories.

The development thus far has been mostly in the direction of fundamental work on theoretical mechanics. In the years to come corresponding staff strengthening should occur to permit the rendering of effective consulting service in thermodynamics, statistical mechanics, chemical physics, electrodynamics, and so on.

During the past year important contributions were made by the section in exact non-linear water wave theory, theoretical elasticity, the theory of elastic surface waves, the theory of diffraction and reflection of electromagnetic waves, and the study of the Fourier transformations for distribution functions occurring in applied statistics.

The strength of the section in carrying on this program of highly original work has been greatly enhanced because the Bureau has been following a wise and highly praiseworthy policy of having on its staff a succession of some of the most renowned mathematical physicists in the world for varying periods as visitors. These have included Stoneley of Cambridge, England, Synge of Dublin, Eire, Schultz-Grunow of Aachen, West Germany, Burgers of Delft, Holland, and Walz of Göttingen, West Germany.

The field of mathematical physics is one that gains in creative productivity in unusual degree from stimulating contacts with great men in the field from other lands. The Bureau is indeed to be congratulated, in the opinion of the committee, on having developed such a first-rate stimulating atmosphere that men of such high distinction find it worth while to spend some time there as visiting research workers, and to give the Bureau the benefit of sharing their latest research ideas. This phase of the program represents a very genuine step forward which deserves every encouragement.

Since further recruiting will be required to maintain the research of this section at its present level of excellence, and to extend their consulting service to other divisions of the Bureau, it may be useful to review the philosophy behind the establishment of Section 11.04, to see how important its maintenance might be. Many Divisions of the Bureau deal with various aspects of classical (nonatomic) physics and, in order to improve their measurement techniques and broaden their service coverage, they require detailed theoretical computations in the fields of classical physics. Many of these computations are difficult enough to be classed as important research projects in theoretical physics, requiring theoretical physicists of exceptional ability to solve them successfully.

One way to get such problems solved is for each Division of the Bureau to hire 
theoretical specialists in their own field, but this has several disadvantages. The number of challenging problems arising in any one Division may not be sufficient to attract the services of a first-class man and the general attitude of the Division may be such as to discourage theoretical research in new directions. Moreover the specialist, being isolated in one Division, may find it difficult to obtain the advice and encouragement from other theoretical workers, in other specialties, which often can make the difference between failure and success in some difficult problem.

Section 11.04 represents an alternate way of providing such specialized consulting services. The theoretical physicists are kept as a group, supporting each other in their work and able to divert manpower, as needed, to various important problems as they arise in the various Divisions. This arrangement utilizes scarce manpower more efficiently and makes it easier to attract good men, but it places a considerable responsibility on the head of the Section to keep in touch with the various Divisions of the Bureau so that the Section can be of real help to them (even, at times, to the extent of persuading the Divisions to get interested in an area which they had neglected before).

If the Bureau is convinced that the maintenance of Section 11.04 is the correct way to provide consulting services for the Divisions on difficult theoretical problems, it must be prepared to make special efforts to recruit the experienced personnel needed by the Section. A Section with these responsibilities, staffed by mediocre people, would defeat its purpose. If such recruiting involves the hiring of specialists from Europe, special arrangements should be made to make this possible.

Respectfully submitted,
\[ \begin{array}{l}\text { A. H. TAUB for the } \\ \text { Technical Advisory Committee } \\ \text { for Mathematics } \\ \text { DAvID BLACKWELL } \\ \text { E. U. CondON } \\ \text { MARK KAC } \\ \text { PHILIP M. MORSE } \\ \text { MINA REES }\end{array} \]

A. H. TAUB, Chairman

Index

In this volume, $M T A C$ has continued its policy of trying to review all published tables, other than the most elementary ones, which depend on or contribute to computation. In addition, there have been reviews of works, essentially book length in size, contributing in some way to numerical analysis or its applications. A classified index attempts to furnish the reader with as much information as is conveniently summarized about these works. The index includes references to tables from number theory, algebra, analysis, statistics and physics, and to works or tables relating to numerical analysis, to the social and biological sciences, and to computing equipment and its use.

In the present volume, the author and the nature of the function tabulated 
are put close together. This is a result of a suggestion by Dr. J. C. P. Miller and seconded by others. In the section devoted to analysis, the classification of the Fletcher, Miller, and Rosenhead Index has been retained without radical change. In the section devoted to statistics, an outline prepared by Professor H. O. Hartley has been used with considerable augmentation. Also, it should be noted that, while analysis tables are assigned fairly consistently to the class to which the tabulated function belongs, the statistics index frequently assigns a table to the section devoted to the use of the function. Some ambiguity in classification is unavoidable, and multiple entries are common.

In the tables from number theory, the classification of the Lehmer Index is followed without essential change (except for the addition of a section devoted to tables pertaining to analytic number theory not suitably assigned elsewhere).

Detail in the classification of the works on numerical analysis seemed justified by the amount of correspondence and conversation which exists concerning adequate presentations of various types of material; this has led to voluminous multiple listings.

The indexing was done largely by the Chairman of the Editorial Committee, but he gratefully acknowledges the help of W. J. Dixon, Rudolph Hüsser, and J. D. Swift - the first two in connection with the classification of tables from statistics, and the last in connection with number theory.

C. B. T.

\section{CORRIGENDA}

D. R. Morrison, "A method for computing certain inverse functions," $M T A C$, v. 10, 1956.

\section{for}

p. 205 , line $-4,1 / 2\left(2^{\bullet}-1\right)$

p. 206 , line $14, f^{-1} \quad f^{-1}$

p. 206, line $-11, f^{-1} \quad f^{-1}$

p. 207 , line $-4 \frac{\pi}{2}$ arc $\cos (1 / y)$

p. 205 , lines $-3,-2$, omit

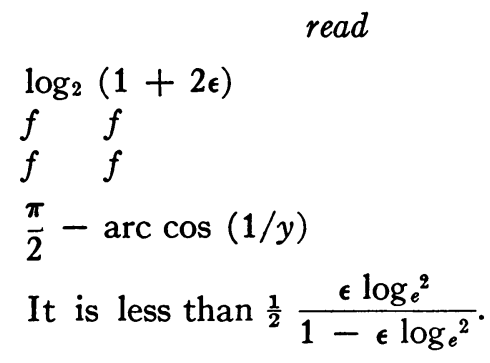

H. J. HAUer

E. A. FAY

U. S. Naval Ordnance Test Station China Lake, California

Review 24, $M T A C$, v. 11, 1957, p. 31, line 3 from bottom, Exponent should read $r$ not $t$. 